\title{
How an Advanced Neurocognitive Human Trait for Religious Capacity Fails to Form
}

Margaret Boone Rappaport

The Human Sentience Project, Tucson, Arizona USA

e-mail: msbrappaport@aol.com

\section{Christopher Corbally}

The Human Sentience Project, Tucson, Arizona USA, Vatican Observatory and University of Arizona Dept. of Astronomy, Tucson, Arizona USA

e-mail: corbally@as.arizona.edu

\begin{abstract}
:
The authors present an evolutionary model for the biological emergence of religious capacity as an advanced neurocognitive trait. Using their model for the stages leading to the evolutionary emergence of religious capacity in Homo sapiens, they analyze the mechanisms that can fail, leading to unbelief (atheism or agnosticism). The analysis identifies some, but not all types of atheists and agnostics, so they turn their question around and, using the same evolutionary model, ask what keeps religion going. Why does its development not fail in one social group after another, worldwide? Their final analysis searches for reasons in important evolutionary changes in the senses of hearing, vision, and general sensitivity on the hominin line, which together interact with both intellectual and emotional brain networks to achieve, often in human groups, variously altered states of consciousness, especially a numinous state enabled in part by a brain organ, the precuneus. An inability to experience the numinous, consider it important, or believe in its supernatural nature, may cleave the human population into those with belief and those with unbelief.

Keywords: agnosticism, atheism, cerebellum, cognitive evolution, Homo erectus, Homo sapiens, neuroscience, numinous, parietals, precuneus.
\end{abstract}




\section{Uniformity with Variation}

Much has been written over the years that tries to define atheism and different forms of it. The best conclusion we can draw from this voluminous literature is that "unbelief," or what we would define as a disbelief in the supernatural, appears in all human societies. Examples come most easily from the socalled Great World Religions - Judaism, Christianity, Taoism, Buddhism, and Islam - because they are well documented.

When we look at non-modern societies, we are mainly convinced of a wide range of religious expression that all other humans appear able to identify as "religious" behavior. Members of some societies are fully involved in religious activities and appear to believe in the supernatural; members of other societies are barely concerned with religious observances, and their range of belief remains unknown [3]. It is precisely in some tribal societies that religious behavior appears, at first, to be most uniform: Everyone participates, everyone goes through rites of passage, everyone seems to believe in the supernatural. And yet, ethnographies routinely capture the contrarian individual who refuses to go along, who leaves and stakes out a new home with a lover he or she should not have, or who simply does not participate and assumes a non-traditional role, like the berdache in a Native American culture who refuses to go along with the entire male role [25]. That non-conforming behavior almost always extends to some change in religious participation, which is tied intimately to conformity. Nonconformity suggests the possibility of unbelief.

When we examine the literature on religion, both modern and pre-modern, we conclude that while some religious behavior appears as a constant from society to society, its level of expression, fervor, or depth is quite varied, from a deep faith in, to an unbelief in the supernatural. Religious expression appears in all known human societies according to the ethnographic and historical literatures, and apparently always has, from the time members of our genus Homo first had religious thinking and engaged in religious behavior. In spite of the uniformity of appearance of some religion in every society, there can be wide variation among individuals. These conclusions are found in surveys of so-called "religiosity" in modern societies [30], [31]. Uniformity with variation in modern Homo sapiens is a judicious place to begin looking at the opposite of religious thinking - atheism and agnosticism. We hinge our analysis on "religious thinking" within a theoretical framework of cognitive archaeology [13]. In modern societies "religious behavior" can be faked and in very early prehistoric societies, there are few finds that suggest religion. We approach religious thinking as a neurocognitive trait that emerged in our evolution.

The logic of our approach is to understand how religious capacity emerged in an evolutionary context, to speculate on how it may fail to emerge in full or fractional measure in living human beings, and then to ask whether we have logically defined all types and degrees of unbelief. Much of our logic is driven by the burgeoning science of human genomics, which shows that very few biological traits are determined by single genes. Human traits - both physical, and the more complexly derived cognitive traits - are driven by multiple, interacting genes. That variety of genes and their potential for variable, phenotypic expression drives the possibility that atheism (or degrees of it, as in agnosticism) could be based upon the expression of many genes and behaviorally, at varying levels of intensity, or not at all, i.e., unbelief. Therefore, this stands as a fertile field for research in the future. At the present, only a very few genes affecting religious thinking have been identified.

\section{Logic, Hypothesis, and Question}

In this paper on atheism, or unbelief, we have chosen to analyze the "failure to form" a human biological trait that is relatively common, but far from phenotypically uniform. This failure can partially explain the degree or level of religious behavior. However, since religious behavior is driven by social factors apart from biology, there is never a clear one-to-one correspondence between biology 
and behavior. And, there is individual, intellectual choice in humans about expressing the trait of religious capacity. Someone may have "the full monty" for religious thinking, but not express it behaviorally. Conversely, another person may have the religious trait to a modest degree but be heavily involved in religious activities.

Therefore, we hypothesize that the biological trait of religious capacity ("religious thinking") has natural variation and at the far end of the scale of variation is atheism. Elsewhere, we have proposed that religious capacity is one of the most complex neurocognitive traits that modern humans possess, and that it makes use of a large number of brain capacities enabled by many brain networks, including, for example, the combined action of the fronto-parietal and the default networks [15], and neural connections between the cerebral cortex and the cerebellum described below [41], [43]. Yet, these are but two of the networks and one pathway involved in religious thinking and theological creativity (defined as the creation of new knowledge using a theory of the relationships between humans and the supernatural that is consistent with broader cultural themes). There are many other neurological capacities involved in religious thinking and participation, including the entire range of brain capacities that manipulate cosmological concepts visuospatially. These include cognitive capacities to imagine and manipulate the self and supernatural beings within those spaces, which are seated, in part, especially in the precuneus [6], [7], [8], [9], [10], [11], [22], [40], [42], [48].

Even with knowledge of only a few genes and several networks at this early point in time, our conviction is that complex combinations of genes and resulting brain capacities routinely produce religious thinking. Religious capacity's emergence - either in evolution or individual ontogeny - is not simple. There is plenty of room for variation and for failure. There may well be increasing variation for the highest, most advanced, human neurocognitive traits because of the increasingly complex genomics underlying them. When we recall that apparently many of the networks used in higher cognitive processes are "exapted" [12], that is, are re-used and re-worked from their original neurological functions, we can see that the process of producing "religious capacity" in a single individual has much room for variation and failure. This is a difference in ontogeny, certainly not a moral failure.

The evolutionary "Building Blocks" identified below make religion not just an idea, but part of our biology through processes whose origins are ancient and overlapping. There is a long history for the biological trait we call "religious capacity" and it has natural variability of phenotypic expression. Some people have what seems like "deep faith," while others appear to have less conviction (whether they behave according to religious principles or in religious activities, or not). Some people show striking creativity in their theological treatises, and others barely connect theology to their worshipful activities. As noted, a "theology" is a theory about the relationships between humans and the supernatural. Theological creativity is not necessarily co-incident with religious thinking, although they tend to overlap, especially for religious leaders from shamans to prelates, who can be quite creative in their interpretations of daily events, dreams, social conflicts, and individual motivations.

The contention that religious capacity is a highly complex neurocognitive trait with broad phenotypic variation is consistent with our hypothesis that it is an evolved biological trait. Many human biological traits are widely held and variably expressed, but some humans do not have them, at all. There are also traits that can be traced to the genomic level, which only certain proportions of humans have. Not everyone has blue eyes. Not everyone is equally hirsute. Not everyone is a "highly sensitive person" [1]. As we learn more and more about the human genome, we see that biological traits can have many separate genes that affect their phenotypic expression. This is solid biology. If religious thinking is one of the most complex, if not the most complex, human neurocognitive trait that now characterizes our species, then we would not be surprised by its absence in a proportion of humans. Biological development of individuals goes awry, with wonderful to tragic results.

We propose that what adult humans ${ }^{1}$ perceive as "atheism" is the absence of religious thinking to a noteworthy degree. Some individuals stand out as particularly unbelieving. They may expound on their views widely or be very quiet about it. They may participate in some types of religiously 
sponsored events, and yet still have unbelief. When recognized, they can encounter an entire range of reactions from exclusion to congratulations. In most modern industrialized societies, atheists are generally accepted socially for most purposes and not excluded from social activities. They join voluntary associations of others who have unbelief. In tribal, non-modern, and evangelical groups, the views of unbelievers can lead to expulsion and even death.

To define those without something therefore hinges upon what capacities others do have, again to various degrees. It also opens the door to the contention that many have made concerning atheism that it somehow causes those humans who exhibit unbelief to see "more clearly" and "more realistically" than others who are "afflicted" or "burdened" by religious thinking. This follows the dictum that religion is the "opium of the people" [26] and that the future for humans involves a clearer perspective that is somehow "free of religious thinking." This logic is quite contrary to religious doctrine, of course, but it is quite cogent. Its opposite is also quite cogent - that religious capacity allows those who have it to "see things" that others cannot fathom, again quite logical.

Let us look at the evolutionary progression that we propose for religious capacity's emergence, and then use that framework to analyze how it could possibly fail in an individual. An analysis of atheism as a failure to form leads unexpectedly to conclusions about religious capacity's fundamental nature, why it is successful in supporting the social group, and why it has become so bound up with social control.

\section{An Evolutionary Model for Religious Capacity Suggests Ways It Can Fail to Form}

We summarize a theoretical model whose foundation lies in research details published previously [3438]. This model traces the biological foundations of religious capacity as a biological trait, and the reader is encouraged to see these papers and the source studies we relied upon. Religious capacity's antecedents are all evolutionary innovations without which today's biologically based capacity would not exist. Some are well known, like Primate sociality, and others are just being discovered, like the importance of the expansion of the cerebellum in higher Primates. Our task was to configure a model based on circumstantial evidence in cognitive science, neuroscience, and genomics, and to project these findings backward to see how they articulate with evidence from paleobiology and "stones and bones" archaeology - always the knowledge base that determines the outlines of our evolution, as we currently understand it. That understanding will surely change, with new discoveries, but we believe this is a good, first attempt. We know of no comparable analysis.

We ask: How did the first and later Primate species need to evolve in order to emerge, 65 million years later, with something like religious capacity in Homo sapiens? When findings from traditional archeology, the new cognitive archaeology, primatology, paleoneurology, cognitive science, neuroscience, population genetics and the burgeoning field of human genomics (of extinct and modern forms) point to the same types of changes, the biological foundation for religion seems more certain. True, it probably did not fully emerge until our species, Homo sapiens, but there were antecedents. The sequence of evolutionary breakthroughs we identify makes religion not just an idea or a cultural fabrication, but part of our biology. Each step through evolutionary time adds a needed biological basis for modern human religious thinking, which is cognitively, emotionally, and intellectually very complex, but is uniform in its support for the social group. Religious capacity may rely on hundreds of brain capacities, if indeed there are thought to be "thousands" [16].

It should be noted that Neanderthals are compared and contrasted with our species repeatedly. Both paleoneurological [6-9] and very new findings on the cerebellum [41], [43] suggest to us that Neanderthals, in all likelihood, did not have religious thinking like Homo sapiens. The archaeological record on Neanderthals remains mixed, and open to conflicting interpretations, although recent genomic studies point to important cognitive deficiencies in Neanderthals, when compared to modern humans [17], [19], [29], [39], [47]. 
We have recently added a new Building Block to our model, which follows the very first one, so it becomes Building Block 2, below. Because this is our first presentation of Building Block 2, we briefly summarize our rationale for inserting it into the original model. Intelligence, as it is determined by the unusual (but not completely unique) expansion and reorganization of the lateral cerebellum, represents an evolutionary innovation, like others, without which religious thinking would not exist today. It is fundamentally an upgrade in sheer computing power plus an ability to store internal models of external models in the ape and human cerebellum, and, for humans, to connect them to expanded association areas in the cerebral cortex. An expansion of the lateral cerebellum is novel to mammals, and for humans, it is connected to "higher cognitive functions" [41].

Our newest Building Block reflects convergent evolution that occurred in three different Orders of the Class Mammalia, including ours: the primates, cetaceans, and pinnipeds (seals). Smaers and colleagues [41] point out that changes in the lateral cerebellum are more reflective of the modularity and interconnectivity necessary for intelligent behavior, than measures of sheer volume would be. Their analysis suggests that cognitive capacities are "scaffolded" by modifications in the mammalian cerebellum, but they only fully occurred in these three Orders of Mammalia. In our Order Primates, it occurred significantly in the anthropoid apes, which gave rise to humans. The authors delve deeply into a statistical proof that lateral cerebellar expansion is strongly related to other measures of intelligence and complex communication. Tanabe and colleagues confirm this interpretation, noting that the cerebellar "neuroanatomical organization may affect innate learning, cognitive ability, and the human capacity to innovate" [43]. We logically connect the ability to handle complex information, and innovate from it, to religious thinking and theological creativity, in fact, all forms of creativity, including art and science.

The size of cerebellar units, which function something like computer chips, is directly related to the number of internal models that humans can store, and the connections to the association areas of the cerebral cortex. Because of these connections to the cerebral cortex, the cerebellum is therefore connected to the primate fronto-parietal network - a feature that is not observed in other mammals. Therefore, the cerebellum is fundamentally involved in human thinking about the supernatural: cosmological space, supernatural beings, and imagining the self in interaction with these beings, in these spaces. Theological creativity uses models to create new stories to illustrate religious teachings, and new religious tenets emerge to summarize these stories. We propose that all these features of religious thinking articulate with the substantial and more general human capacity to manipulate visuospatial information (real or imaginary), especially in the parietal lobes. Three-dimensional imagination is central to physics and to theology, although both rely on many more human brain capacities, too.

Cerebellar re-organization comes after our first foundational Building Block, which represents a more general feature of all Primates (not just the anthropoid apes) - sociality. We place re-organization of the lateral-medial cerebellum after (in evolutionary terms) primate sociality and before the emergence of the first true ape, Proconsul (Building Block 3). Various ranges of dates are given for Proconsul, from 23-25 mya [million years ago] to 14-23 mya. The more general term, proconsulids (representing 10 different genera) date 17-22 mya. Our sequence of Building Blocks assumes that cerebellar-cortical reorganization was ongoing somewhat before Proconsul fully evolved, and that the species stabilized around our estimated date for Proconsul of 19 mya.

The evolutionary emergence of religious capacity in the genus Homo relied upon the following 10 Building Blocks:

Building Block 1. Sociality in all primates, 65 - 55 million years ago.

Building Block 2. Reorganization of the lateral-medial cerebellum in the anthropoid apes, Order Primates, leading to modularity and increased capacity to store internal models, and, interconnectivity between the cerebellum and the association areas of the neocortex [41]. The result was "intelligent 
behavior" and ability to innovate [41] [43]. We see this ability to innovate in science, art, and religion of Homo sapiens.

Building Block 3. A basic ape model from the Miocene, beginning around 19 million years ago, with Proconsul, the first true ape.

Building Block 4. Realignment of the senses, with upgrades of vision and hearing on the line to humans and some modern apes.

In some groups of the ancestral ape population giving rise to the genera Homo and Pan in Africa, Building Blocks 5 - 9 emerge:

Building Block 5. Lengthening developmental trajectory or "secondary altriciality" and the downregulation of aggression, 8 - 10 million years ago.

Building Block 6. Greater social tolerance among adults, especially while feeding.

Building Block 7. Further upgrades in intellect to help to manage aggression in the social group.

Building Block 8. Greater sensitivity emerges, both general sensitivity (in terms of heightened awareness and preparation for action), and sensitivity that engages the emotions.

Building Block 9. Biological foundations for culture emerge in ancestors to both Homo (strongly) and Pan (weakly). The first evidence for culture in our genus was in Homo habilis, who made the first stone tools found in the archaeological record. Culture also likely characterized earlier, bipedal Australopithecines, who did not have shaped-stone tool traditions, but probably used stones to butcher. Moral and religious capacities emerge relatively late - moral capacity in Homo erectus and religious capacity in Homo sapiens.

Building Block 10. Moral capacity emerges in Homo erectus, 1 - 1.5 mya, after the species controls fire and a learning context called "The "Human Hearth" develops. The reader is referred to the full theoretical development of this model [32-33], which includes cognitive features that characterize rudimentary morality and gives research findings that support their presence. Phenotypic expression of moral capacity in Homo erectus (and later in Homo sapiens) include all of the following at the same time:

a. A mental step both back and up

b. An arbitration mechanism that operates along a timeline

c. An evaluation using a valence from good to bad

d. A regretfully dispassionate reasoning

e. A tentativeness in a mental balancing act

f. A sad rejection of "wantonness"

g. A capacity for empathy with someone receiving moral judgment

h. The experience of a burden

i. Resolution on the part of the group

j. Hope and faith in the future on the part of the group

Our model includes the emergence of religious capacity in Homo sapiens, stabilizing at around 120,000-130,000 years ago, according to studies on globular brain shape of fossil skulls [34-36]. Skulls began to round in a manner typical of the more modern human species before this, by around 300,000 year ago, according to finds from Jebel Irhoud, Morocco [23]. The human skull began to round in response to the expansion of brain tissues beneath, particularly the precuneus, part of the parietals [69], but also due to the enlargement of the cerebellum and other underlying brain tissues [19]. In this latter study, there is evidence that the cerebellum was an important difference between Homo sapiens and Homo neanderthalensis.

We understand "theological creativity" as part of the development of religious capacity in Homo sapiens alone. Through time, theologies were shaped increasingly by various cultures so that they are consistent with other cultural themes. However, they maintain a remarkable number of fundamental similarities cross-culturally, and despite their differences, testify to a single neurocognitive origin for religious capacity and theological creativity in our species. Our model 
includes the earlier emergence of moral capacity in Homo erectus, but not religious capacity. Our view is that Homo erectus may have had chanting, percussion, and storytelling, but only in Homo sapiens is there music, a capacity enabled, again, by the precuneus in the modern human parietal lobes. Furthermore, modern humans are the only ones to have internally consistent and structured theories about the relationships between humans and the supernatural. Religious and moral capacities are usually intimately joined in modern humans, so what is true for moral capacity remains true for religious capacity. Yet, even now, moral and religious capacities are separable, both theoretically and practically, as many types of organizations involve moral thinking but are not specifically religious.

The fact that moral and religious capacities can be conceptually teased apart is particularly important for our task related to atheism, i.e., identifying mechanisms whereby religious capacity fails to form. If religious and moral capacities are separable, moral capacity can be present without necessarily its frequent conveyor (religious capacity), and that makes sense from what we know of the modern atheist: They are "without God," so to speak, but not necessarily without morality, as with "ethical humanism." Before we go on further to address the nature of religious capacity and its absence, let us first look at which Building Blocks suggest mechanisms that might fail, and therefore produce unbelief or atheism.

\section{Mechanisms Whereby Religious Capacity Can Fail to Form}

We now use our evolutionary model as an analytical framework to discover possible ways in which religious capacity could fail to form.

\section{Building Block 1: Primate Sociality}

There are myriad ways in which social development can affect a proclivity for unbelief or atheism. Parents and family members may profess little faith or choose not to participate in religious activities. The question then becomes whether an assumption of unbelief by a family member results from inheritance, learning, or both (the nature/nurture question). More fundamental for the adult atheist might be either an event that encouraged or signaled unbelief, or a conscious choice - an intellectual conclusion - that unbelief made the most sense. Then, there would be a choice as to whether to accept the social consequences of unbelief, especially if they are onerous. Unbelief would become a life choice, like political party, and it would be shorn up by others characterized by unbelief.

On one end of the sociality scale are individuals who are developmentally delayed and not intellectually capable of participating in the society's usual religious activities. This can result, for example, from a social anxiety disorder or a genetic disorder along autism-schizophrenia scales that prevents the more usual, mutually satisfying, and effective social communication. This also includes some very intelligent individuals with severe autism who are disabled in terms of social communication. Developmentally delayed and autistic humans are usually not be able to comprehend basic tenets of a religious creed, its logic, ethics, lifeway, or its supernatural beings. While some creeds identify the disabled as "touched by the supernatural," this appears to be a culturally fabricated explanation, perhaps to soften a sense of helplessness or fear. The analysis in this paper strongly suggests that humans with very low intellect are rarely able to participate either socially or intellectually in religious thinking or religious life. Indeed, their inability provides support for the heightened intellect needed for religious thinking that is found on the evolutionary line to modern Homo sapiens.

For our evolutionary model, we are reminded that religious capacity tends to involve a person with other people, in social groups and in whatever rituals are required and whatever social events mark the calendar. Religious capacity does not quite make sense except in a social context, as part of a social institution and support for it, and, as the result of social learning. True, there is the lone monk 
worshipping by himself, but his doctrine and usually his rituals rely on a belief system fashioned by others. We conclude that primate sociality - so old and so fundamental to how we live our lives - is sine qua non for religious capacity. So, what of the humans who have no belief? They can be left stranded socially, or they can be free to choose another social group in modern societies. That freedom is appealing to some people who evidence unbelief. Atheism does have the effect, especially where there are other choices readily available, of "freeing" an individual from some social strictures, but not all.

\section{Building Block 2: Primate Reorganization of the Lateral-medial Cerebellum}

There are many different ways that intelligence can affect unbelief or atheism. Many of those who write on atheism make cogent arguments for atheism, and it is clear that they have read on the subject and want to communicate the reasons for their unbelief and that it is a valid choice. Atheism can take on a proselytizing function for some people, which is not unlike efforts to convert others to a religious belief system. Not unexpectedly, the more intelligent the unbeliever or the believer, the more elaborate and convincing the argument.

On the other end of the intelligence scale are developmentally delayed individuals who are not intellectually capable of meaningful participation in most religious activities. These individuals are not able to comprehend basic tenets of a religious creed, its logic, ethics, lifeway, or to interact with its supernatural beings in culturally prescribed ways. That is a great deal to learn, and again, this quantity of material (especially in non-literate societies with oral traditions) testifies to the need for a substantial amount of intelligence to remember and make sense of it all. It is important to remember that we refer to intelligence within an evolutionary context. There is a normal range of human intellect that is required for most types of religious thinking. If we assume that full intelligence comparable to today's modern humans has some relation to cerebellar re-organization, then we conclude that there is some minimum intelligence beneath which a species cannot engage in religious thinking. Homo erectus, for example, probably did not have the cerebellum (or other brain organs) of modern humans (indeed it is obvious from fossil skulls that the species did not), and this may be related to a lack of religious thinking. This is a preliminary contention on our part, but one based on an increasing number of findings from the modern sciences [32], [33].

We have often read authors (both those with belief and those with unbelief) who complain that religion removes the need to think and decide for oneself. Religion is sometimes seen as the "easy way," i.e., to go along with everyone else in accepting a theological interpretation. One simply does what religious doctrine dictates. However, religious thinking and participation are not quite that simple - a notion that is a surprise to many. Religious precepts take considerable thought to follow judiciously. True, religious beliefs can be "faked" but it takes a great deal of energy to lead a completely fake life. One corollary is true: If one finds that unbelief is the only tenable choice, that choice can have mild-tosevere social consequences. Choosing unbelief is a somewhat risky option, again underscoring the social foundation of religious capacity and its principal function in supporting the social group.

\section{Building Blocks 3 and 4: Our Basic Ape Model; and, Better Vision and Hearing}

Religious capacity is dependent upon the type of mammalian model we came from. The characteristics of our ancient ape ancestors were critical for what eventually emerges in our species as religious capacity. For our evolutionary model, we can see from primatology studies [14] that apes must have already been evolving in the directions that humans would assume in part, change in part, and use in 
their own way. Therefore, it is useful to look at features of all apes, especially in modern apes. They are often called "relics" of a large and widespread populations of apes that were plentiful in the Miocene.

Apes are large, they develop slowly, they have big brains, and they are demonstrative, at times. They are also fundamentally social, they live in troops, and child-rearing is lengthy and intense, forming bonds that last for years. Apes also have no tail, which requires flexible and strong limbs and torso to stabilize movement and sitting. Those requirements are all retained by humans, who are flexible, demonstrative (at times), intelligent, and form deeply emotional bonds with other humans.

Humans who have no religious beliefs inherit all these traits, as do humans who have religious beliefs. We would not distinguish humans with unbelief on the basis of most of these features. We find few mechanisms that would cause religious capacity to fail to form, unless it is a fundamental failure in ontogeny in the development of sociality, intelligence, or ability to form emotional bonds with other people. Those incapacities could contribute to atheism or unbelief - or vary with it - because of the social and often emotional nature of so much, but not all, of religious experience.

We see the ape demonstrative tendency as fully congruent with many religious behaviors, especially for religious leaders but also for followers. Our improved vision and hearing make participation in religious activities substantially more intense. For example, human senses are fully at play in what we would term "numinous experience" that occurs so often in a variety of guises in most, if not all, religions. To the extent that improved senses heighten numinous experience, we conclude that heightened senses could support the emergence of religious capacity.

\section{Building Blocks 5 and 6: Lengthened Developmental Trajectory; and Social Tolerance in Adults}

During its lengthy evolutionary emergence, religious capacity depended on sociality in its basic form of living in troops (later groups or bands). It also depended on cooperative social activities of groups of adults and helping others with tasks of a physical or intellectual nature. Complex social participation by adults would not be possible with an aggressive orientation like that of modern chimpanzee. Religious activities often involve bringing other adults close, in order to prepare for or take part in rituals, teach lessons, and render assistance. Young anthropoid apes, like many immature mammals, socialize easily, so they are naturally accepted and included, but when adulthood is reached, this easiness is uncommon.

For our evolutionary model, changes had to occur to the more generally aggressive stance of adult great apes, or religious capacity could not have emerged. While ape juveniles play freely, adult apes tend not to socialize quite so much or so easily, with the exception of bonobos [20]. Our view is that their ancestors must have developed a parallel down-regulation of aggression, as in groups leading to humans. We hypothesize that a less aggressive adult style of interaction was achieved by extending juvenile socialization into adulthood, according to a "domestication" syndrome or suite of changes well outlined in other animals [20]. Modern apes show a variety of adult personalities and social styles, from the more aggressive chimpanzees to the more docile bonobos. Gorillas fall somewhere in between, although they can be aggressive when provoked, as can the rest, including the derivative human. Still, the level of cooperation achieved by adult humans is not seen in any other mammals.

Before the genera Homo and Pan diverged, other changes were happening to ancient Miocene apes that humans have inherited and accentuated. They involved a lengthening of the developmental life cycle, so that individuals matured more slowly, were dependent for longer as juveniles, and adults had greater longevity. The pattern is called, "secondary altriciality," implying a secondary and a longer period of dependence (primary altriciality being at birth). Childhood lengthened and adolescence emerged, when before, there had simply been two age groups, the young and the adults. We hypothesize that, along with this lengthening maturation, some features of immature apes were retained into adulthood, especially the social tolerance of others and a behavior profile that encouraged it. Above, we even likened it to the profile for domesticated animals. In general, some ancient apes 
became more tolerant as adults, with the possibilities opening up for cooperative group activities that emphasized interaction and heightened emotional experience. All of this would not be possible if some ancient apes had not evolved to mature more slowly with a changed temperament.

How does this emergence help us to examine atheism and unbelief in later humans? The answer may again come down to conformity and risk. We begin to see how the social exclusion of atheists may be something anticipated by them and, if necessary, tolerated. In other words, unbelief carries implications about sociality, tolerance, and cooperation. To choose disbelief requires some risk because of the possible exclusion of the atheist from some or all social roles and activities. We suggest that individuals with unbelief come to understand this risk and decide to either tolerate it or not. Indeed, people who profess unbelief in the modern world are taking a stand, which separates them from others who profess belief [30], [31]. To carve out a place for oneself that is separate runs contrary to many of the evolutionary social changes underlying religious capacity. Humans with unbelief naturally separate themselves from humans with religious capacity by their non-conformity alone.

\section{Building Blocks 7 and 8: Further Upgrades in Intelligence to Manage Aggression; and Greater Sensitivity}

When tolerance among anthropoid adults increases, so do the complexities of social life. This puts a premium on sensitivity, both a type of sensitivity that is connected to the network of emotion centers in the brain, and a type of sensitivity that is not, which is likened more to a type of awareness and readiness for action. Two types of sensitivity have already been connected to genomic segments, and scientists anticipate that there will be many more genes that affect sensitivity in the future [4], [1], [35], [44], [45].

Social sensitivity in humans is a complex characteristic whose genomic underpinnings are multiple, some known and some unknown. There is plenty of room for failure in the mechanisms and pathways that guide social life, as well as fractional activation at multiple levels and perhaps, additional loops and sequences that involve decision making and additional aspects of primate sociality.

\section{Building Blocks 9 and 10: Biological Basis \\ for Culture Emerges; and Then, Moral Capacity}

In the ancient apes that eventually gave rise to the human and chimpanzee lines, around 8 to 10 million years ago, a cognitive capacity for culture arose. Today, we see culture only weakly in the chimpanzees and bonobos, but very strongly in humans. Culture is different from sociality, which characterizes all primates in many different configurations. Sociality is about group life - how it is configured, how dominance and nurturing are provided, and the group's functioning as a unit in provisioning themselves and defense from predators. It is said that social primate groups evolve as a group, and while individual members are the ones to convey the group's genetics, there is much truth to the notion that the group is the adaptive unit for evolution.

This changes things and sets the stage for the emergence of a trait that strengthens the group even more. Cultural capacity is biological, but culture itself is learned, passed on within the group, and because it is largely a cognitive trait, opens wide the possibility for cultural differences between groups, even if they sometimes interbreed. Culture can change over time, while new technologies are crafted, refined, and then discarded, and new customs emerge to define the group's identity. Its succession is not, itself, generally dependent on genetics, although we are learning more and more about culture-biology loops where the two adaptive systems affect each other.

Culture is learned by the young at a time when they are receptive. To the child, it appears natural, and they are unaware of learning much of it. It also takes attention by older individuals, purposeful teaching and learning, and therefore culture is highly dependent on the lengthened 
developmental trajectory described above, and on early and long-lasting bonds between individual members of a troop - eventually, a human group, once the line to modern humans diverged around 6-7 million years ago. It was not until around 3 million years ago that the genus Homo emerged. By around 2 mya, Homo erectus emerged - fully bipedal, with a fully developed stone tool tradition that changed gradually. By about 1.5 mya, Homo erectus had learned to control fire, if the latest remains of fire making from Wonderwerk Cave in South Africa continue to hold [5].

It is in the species Homo erectus that we propose moral capacity first arose and was perpetuated culturally in a learning context we call "The Human Hearth" [32]. Fundamentally, moral capacity is a cognitive trait that is a biologically based facility for decision making based on neuronally encoded values [36]. Its phenotypic expression varies widely, but not as widely as often assumed, because there are broad cognitive similarities in the adjudication of different moral systems. For morality and most aspects of human life, culture defines what is real and not real, right and wrong, desirable and undesirable, for specific groups of humans. That gives several good clues about atheism, or the failure to form religious capacity in modern humans.

Religious thinking is a biological trait that uses cultural capacity to define cosmologies, to populate supernatural spaces, and importantly, to specify behavioral rules in the form of ethics. We have speculated that ethics derive, in general, from ideal characteristics of supernatural beings. Their qualities become guidelines for behavior to which humans can aspire. In many ways, the atheist could be defined as rejecting certain basic aspects of the cultural belief system held by people in his social group. The questions remain: Is this an intellectual choice, part of a biological trait that fails to form, or both?

We do not interpret cultural capacity, moral capacity, or the later, religious capacity, strictly as "adaptations" because there are strong indications that random genetic drift in small groups of apes and hominins may well have influenced the retainment of traits, in addition to natural selection. In particular, there is an absence of many "selective sweeps" in the human genome and the presence of much "neutral" material [21], [24]. Genetic drift is much stronger than natural selection in small groups, so the effects of natural selection were dampened. Genetic drift is a random, not a directional force, and was probably an important factor in the emergence of the special neurocognitive traits that make humans so special. We propose that cultural capacity probably arose in small groups of late apes or early humans, and remained because the groups were isolated, and natural selection was weak. The trait may have arisen more than once and may not have been immediately beneficial. It could even have been "slightly deleterious" - the term now used for traits that remained in the human genome and caused some damage, but not too much, or, in another environment, became beneficial.

Cultural capacity and the much later religious capacity emerged initially by chance, were retained, and later became useful to the social group. It is possible that religious capacity was retained because it had features that were physically and psychologically pleasing to humans. For early humans who were beginning to shoulder the burden of self-awareness, any altered state of consciousness might have had an appeal. By the time of Homo erectus, who hypothetically enjoyed a rudimentary morality and moral adjudication with the characteristics listed above, it is very likely that the human line was beginning to view its place in the universe (however that was conceived) and responsibilities to the social group were taking on moral dimensions. Recognizing these moral aspects of group behavior can be a heavy burden. Our contention is that this burden was, and remains, eased in Homo sapiens by religious capacity.

How can this inform our view of unbelief? It suggests that the atheist or agnostic has escaped the burdens of self-consciousness and found supports that can substitute for religious behavior and its expression. Another possibility is that the burden is borne entirely by science and the human intellect. This possibility forms an important part of the modern literature on atheism. What is noteworthy to us is that, for the most part, the argument is not adopted by many humans, at least yet. If religious capacity is the biological trait we identify, then it will come under enormous selection pressure in the modern 
world, with its billions of humans. It is on large populations like the world (and soon off-worldly) human populations of today that natural selection will exert a newly strengthened influence. How will religious capacity fare after those pressures? Will religious capacity be genetically wiped out, or will it remain standing? Or, will it become something else?

\section{Who Are the Humans in Whom Religious Capacity Fails to Form?}

We have examined developments - biological innovations - that were foundational to religious capacity. We have speculated on reasons it may fail to form in some living humans. We conclude that religious capacity requires a basic sociality, but also special senses and sensitivities that enhance sociality and allow adults to approach each other and gather in groups for religious purposes. We have discovered that religious capacity entails good intelligence (from an evolutionary viewpoint), and that both sociality and intelligence are especially important for religious leaders. We conclude that any developmental problem that might impact social life and communication, or that severely limits intelligence, can well give rise to religious capacity's "failure to form."

We have also mentioned that religious and moral capacities involve intellectual decisionmaking capacities, and we have noted that many modern humans make a choice to adopt atheism or agnosticism for rational reasons. They know, understand, and appreciate social life, but are intellectually convinced that atheism is the right path. They can work well in groups, and sometimes stand out for their leadership. They tend to be socially aware, but simply choose another system of belief. Atheists who write of their "conversion" to unbelief, or atheists whose goal is to be "free" of religious thinking and experience, are generally in this group. Their belief system makes an intellectual statement and a life style choice. We note that agnostics and atheists sometimes appear in various states of indecision. This can be a very large number of people, which varies from society to society, and with stage in the human life cycle. Many young people question the religious and political beliefs of their parents. Is this a failure of religious capacity to form? We believe not. We see it as a stage in formation, where individuals consider the consequences of their involvement, and make a decision for belief or unbelief.

On the opposite end of the decision-making spectrum, we next mention a small percentage of humans who do not have moral capacity, and therefore religious capacity, at all. They have no "moral compass," and no decision-making apparatus that helps to define "right" from "wrong." These individuals can appear oddly out of tune to others when, for example, it comes to events that cause others to be squeamish, such as the killing of animals for no worthwhile purpose, or torture. They may find religious thinking beyond their ability, although they can appear quite intelligent in other ways, and live among others and even participate in religious activities. Still, they are often in an uneasy alliance, and others tend to sense their disjuncture. Individuals without a moral compass can be aware of it and good at hiding it. They tend not to have an interest in religious thought or experience, except for self-serving reasons.

We are left with questions about why some individuals choose to withdraw from religious participation, and why others remain fully committed to it. In the past century, in many modern and developing societies, we have seen the rise of a rationale for many females to withdraw from religious institutions, and it is seated in the traditional aspects of religious doctrine that they deem sexist, discriminatory, and even cruel. Yet, other women participate in religious activities and try to change rules from within. Socioeconomic factors can also be just as strong as gender in encouraging others to leave a religious institution or stay with it. And still, when all of the demographic factors are considered, we are not sure we understand why some humans have belief and others have unbelief.

Let us turn our questions about atheism and ask an obverse question. Instead of examining why atheists choose to relinquish religious experience, perhaps we should examine why others choose religion. Can a model of the evolution of religious capacity and knowledge of cognitive science and 
genomics shed any light on why religious thinking and experience are sought? This approach may lead us closer to an understanding of why religious capacity can fail to form or not form fully. We are looking for some essential feature or features that believers want or need, which traces back to a critical evolutionary development on the human line. Our evolutionary "Building Blocks" explain a sequential foundation for religious capacity, and where it came from biologically. Now, we are required to explain how - or what - keeps it going. Why do more people not leave religion and opt for atheism, or at least agnosticism?

\section{Origins of the Numinous and Its Modern Function in the Genus Homo}

If we examine the features of ancient apes that had to change in order for religious capacity to flower millions of years later on the human line, we may find a clue that will help to explain humans' continued capacity and desire to experience religious thinking. It is not enough to call religious thinking a "biological trait," which it is. However, there is a choice concerning the expression of that cognitive trait, as there is with, for example, reading. This ability to decide can lead to some humans opting out, at whatever level of political and social development they exist, from tribal to modern nation-state. We search for something new and special that came with the human evolutionary line, which goes far in explaining why some humans steadfastly adhere to a life in which religious thinking is important. What keeps it going?

An analysis of atheism as a failure to form has unexpectedly led to conclusions about religious capacity's fundamental nature, why it has been successful in supporting the social group, and why it has become so bound up with social control. When we listed the evolutionary upgrades that occurred in some groups of late Miocene apes, we included improved senses, especially in vision and hearing. We also noted how these senses came to heighten the experience of modern humans in religious activities and to make their experience more intense, and in some way, more satisfying. We also described a tendency for a demonstrative quality in ape behavior, from time to time, and found it fully congruent with many religious and artistic behaviors in their descendants. Religious activities involving the senses range from the very active, loud, and dramatic, to the quiet, thoughtful, and subtle. To the extent that improved senses today heighten the experience of religious participation and lead to what some have labeled "a numinous state," we conclude that the heightened senses emerging in some ancient apes could have supported the evolution of religious capacity, and perhaps, helped to keep it going in the lives of humans.

The observation of a connection between types of senses that were upgraded on the human line, and continued capacity and desire for religious thinking may be a new type of observation, but the observation that the numinous is important is surely not new. Still, our goal is to understand religious capacity's failure to form, and in biologically determined senses we may find a clue. Where these senses are not present, or not finely tuned, their absence could help to explain atheism. Those who choose atheism may not achieve a sensory "high" from religion, and therefore choose unbelief because of the long-researched "costs" associated with religious participation. When questioned, the humans who believe in the supernatural repeatedly refer to experiencing something like "numinous experience" as one of religion's main attractions. We add one additional and very important factor. Individuals on the human line, at least from the time of Homo erectus [13], had a daily model of the numinous to which they could point - dreaming.

We have crafted our contention very carefully, because for some scholars, the "numinous" is non-sensory, non-rational, and not detectible by science, i.e., it is a "non-sensory feeling" [28]. The latter could be called an oxymoron, and indeed we believe it is. While some altered mental states may seem divorced from sensory experience (like dreaming, hallucinations, and drug states, to name a few), we understand the human body to be the interface with the outside world. Sensory experiences based in the environment are coded in the human nervous system, even if they come to be interpreted differently 
later. We do not believe that the notion of "numinous experience" needs to be, or indeed can be, separated from the human senses. Therefore, we look to human senses as a model for numinous experience. Often, sensory terms are all that humans have to describe the numinous.

The notion that experiencing the numinous is separate, outside the self, and that the individual experiences it as "ganz Andere" [German, completely different] or "wholly other" is a very appealing idea that, in its error, manages to capture much of the appeal of religious experience: It takes the person somewhere that he or she usually does not go. In understanding the appeal of the numinous, we come to see that it is seated in normal human sensations that are derived from the experiences of the human body [27], but that the numinous often comes to be interpreted as supernatural. Why would the experience of a mental state called "numinous" be so widely appealing, become so culturally meaningful, and why is it connected so easily to the supernatural - worldwide?

For the atheist, there must be a fault in the following progression. Either the atheist does not experience the numinous, does not want to, finds it too frightening, does not find it culturally meaningful, or does not connect it to the supernatural. Furthermore, the atheist surely has difficulty with religion's unfailing support for the social group and especially, its connections to social control. Let us take a closer look at the concept of the numinous, and how it strikes scholars and the devout, alike.

Rudolf Otto, who helped to popularize the concept of the "numinous" [28], believes that it cannot be defined in terms of other experiences. He finds that it is not perceptible by human reason, and it is a mystery both terrifying and fascinating [mysterium tremendum et fascinans] [2]. In The Idea of the Holy, Otto writes:

The feeling of it may at times come sweeping like a gentle tide pervading the mind with a tranquil mood of deepest worship. It may pass over into a more set and lasting attitude of the soul, continuing, as it were, thrillingly vibrant and resonant, until at last it dies away and the soul resumes its "profane," non-religious mood of everyday experience... It has its crude, barbaric antecedents and early manifestations, and again it may be developed into something beautiful and pure and glorious. It may become the hushed, trembling, and speechless humility of the creature in the presence of - whom or what? In the presence of that which is a Mystery inexpressible and above all creatures [2].

From an evolutionary perspective, the following words are particularly important: "It has its crude, barbaric antecedents and early manifestations..." These are the origins of the numinous in upgraded human senses. We ask: When and how did the numinous emerge as a mental state that members of our genus Homo could enjoy and in which they could find solace and relief? It may have begun at the time of Homo erectus, in a context we call "The Human Hearth," where a Homo erectus band met around a campfire to recount stories (in a language that was not yet fully grammatical according to some, and fully grammatical, according to others). They discovered the right and wrong of the day, and first conceived of a supernatural spirit [32-33]. Is that when the numinous began to be appreciated? Perhaps, or perhaps it had to wait for the larger capacity of the Homo sapiens brain, especially portions of the parietal lobes and the precuneus, whose partial de-activation is known to cause dream-like states. According to research, the modern precuneus could be capable of manipulating counterfactual places and beings. Religious thinking could not exist without the expanded precuneus of our species. Still, to follow the logic of evolutionary science, it almost surely began with antecedents we can begin to identify now. 


\section{Conclusions}

We have worked our way through the biological origins of religious capacity, and we have searched for antecedents of present-day types of thought and activities. We first asked how religious capacity formed, and then speculated on how it could "fail to form" and lead to atheism or unbelief. We identified some types of humans in whom religious capacity does not develop, take hold, and emerge according to cultural motifs of the person's society. However, we still could not identify, at first, the feature that "failed to form." Therefore, instead of asking why and how religious capacity could fail to form, we asked the obverse: What keeps it going? Why do humans not all simply relinquish religion and all its strictures, and take up a life of unbelief? In the progression we sketched earlier, we find all types of evolutionary innovations that led to religious capacity, from a downregulation of aggression to an upgrade in social sensitivity. The changes in the senses were simply noted as important because they help to make religious group activities so meaningful, with songs, chants, lighting, shadows, and the drama of religious ritual. We searched and found the seemingly, only vaguely important upgrades in the senses. That suggested some change in the senses that might give humans motivation to come back to religious thinking, time and again. It had to be something that relied on evolutionary changes but gave them motivation, now and into the future.

We had to go further. In our focus here on the numinous, we slip from direct sensory experience to sensory experience that is not, ostensibly, of this world. That is the "theory" embedded in the "theology." The fact that it is indeed of this world can be logically set aside by believers because of its appeal. In the course of religious worship, the worshippers do not care. Religious doctrine and ritual make the other-worldly, real. Recall, culture defines what is real and not real, and it accomplishes this through religion and other institutions. The numinous combines known sensory experiences into a jumble of vague feelings that lose their comparison with mundane human life. The numinous provides an altered state of consciousness that can be easily sought, obtained, and left behind when a religious activity ends. There is no need for drugs, although drugs are often used in religious rituals. There is no need for extremity or pain to achieve a hallowed state. The numinous is its own, low-level, sensory "high" and it forms an important part of the basis for why many humans participate in prayer, offerings, services, music, singing and chanting.

If desired, atheists and agnostics can find the numinous in nature, as did Ursula Goodenough in The Sacred Depths of Nature [18]. On the other end of the intensity scale, Alvin Toffler, in Future Shock [46], foresees an entire industry of "Experience Makers," while the manufacturing and service industries fade away. "Experience" will be a commodity like all others - planned, exquisitely packaged and delivered, and often completely simulated. Why would this be the industry Toffler foresaw - other than the fact that even in 1970 , it had already begun to form?

What do we have now that meets those needs? We have art, music, science, and we have religion. In mankind's long progression from his origins among the ancient apes of Africa, he has sought release, amusement, delight, and escape from the self-consciousness that evolution handed him. It is a heavy burden, to see oneself on a timeline, to know of one's ultimate demise, to realize that mistakes can be made that hurt others, and to willingly accept the ultimate control of the social group. All of this is a burden that needs healing. We as a species were dealt a heavy blow. We know right from wrong. We live self-consciously and tentatively, and we relish the experiences that can shoulder part of that burden just a little bit of our time on Earth.

\section{Epilogue}

Not surprisingly, the two authors have different perspectives in light of the analysis in this paper. One, an anthropologist, is probably closest to an agnostic, although she has experienced the numinous in religious services. The other, an astronomer but also Catholic priest, sees "crossing over" to a belief in 
the numinous as "a gift." In spite of these two very different perspectives, it is interesting that the analysis stands.

\section{References}

1. Acevedo, B. P., Aron, E. N., Aron, A., Sangster, M.-D. Sangster, Collins, N., Brown, L. L. The Highly Sensitive Brain: An FMRI Study of Sensory Processing Sensitivity and Response to Others' Emotions, Brain and Behavior 4, 2014, pp. 580-594.

2. Alles, G. D. Ed. Autobiographical and Social Essays by Rudolf Otto, De Gruyter Mouton, 1996.

3. Barth, F. Nomads of South Persia: The Baseri Tribe of the Khamseh Confederacy, Little, Brown, 1961.

4. Beevers, C. G., Ellis, A. J., Wells, T. T., McGeary, J. E. Serotonin Transporter Gene Promoter Region Polymorphism and Selective Processing of Emotional Images, Biological Psychology 83, 2009, pp. 260-265.

5. Berna, F., Goldberg, P., Horwitz, L. K., Brink, J., Holt, S., Bamford, M., Chazan, M. Microstratigraphic Evidence of In Situ Fire in the Acheulean Strata of Wonderwerk Cave, Northern Cape Province, South Africa, Proceedings of the National Academy of Sciences 109, 2012, pp. E121520.

6. Bruner, E., Iriki, A. Extending Mind, Visuospatial Integration, and the Evolution of the Parietal Lobes in the Human Genus, Quaternary International 405, 2016, pp. 98-110.

7. Bruner, E., Pearson, O. Neurocranial Evolution in Modern Humans: The Case of Jebel Irhoud 1, Anthropological Sciences 121, 2013, pp. 31-41.

8. Bruner, E., Preuss, T. M., Chen, X., Rilling, J. K. Evidence for Expansion of the Precuneus in Human Evolution, Brain Structure and Function 222, 2017, pp. 1053-1060.

9. Bruner, E., Spinapolice, E .E., Burke, A., Overmann, K. A. Visuospatial Integration: Paleoanthropological and Archaeological Perspectives, In The Evolution of Primate Social Cognition, Springer, 2018, pp. 299-326.

10. Cavanna, A. E., Trimble, M. R. The Precuneus: A Review of Its Functional Anatomy and Behavioural Correlates, Brain 129, 2006, pp. 564-583.

11. Cavanna, A. E. The Precuneus and Consciousness, CNS Spectrums 12, 2007, pp. 545-552.

12. Coolidge, F. L. Exaptation of the Parietal Lobes in Homo sapiens, Journal of Anthropological Sciences 92,2014 , pp. 295-298.

13. Coolidge, F. L., Wynn, T. The Rise of Homo sapiens; The Evolution of Modern Thinking, WileyBlackwell, 2009.

14. De Waal, F. Primates and Philosophers: How Morality Evolved, Princeton University Press, 2009.

15. Dixon, M. L., De La Vega, A., Mills, C., Andrews-Hanna, J., Spreng, R. N., Cole, M. W., Christoff, K. Heterogeneity within the Frontoparietal Control Network and Its Relationship to the Default and Dorsal Attention Networks, Proceedings of the National Academy of Sciences, 201715766, 2018. Published online ahead of print. https://doi.org/10.1073/pnas.1715766115

16. Gazzaniga, M. S. The Interpreter Within: The Glue of Conscious Experience. Dana Foundation web site, Gazzanig's blog, 1999.

http://www.dana.org/Cerebrum/Default.aspx?id=39343\#sthash.I7zCiFeL.dpuf

17. Gómez-Robles, A., Sherwood, C. C. Human Brain Evolution; How the Increase of Brain Plasticity Made Us a Cultural Species, MÉTODE Science Studies Journal 7, 2016. [no page numbers] https://doi.org/10.7203/metode.7.7602

18. Goodenough, U. The Sacred Depths of Nature, Oxford University Press, 1998.

19. Gunz, P., Tilot, A. K., Wittfeld, K., Teumer, A., Shapland, C. Y. Shapland, Van Erp, T. G. M., Dannemann, M., Vernot, B., Neubauer, S., Guadalupe, T., Fernandez, G., Brunner, H. G., Enard, W., Fallon, J., Hosten, N., Volker, U. Profico, A., Di Vincenzo, F., Manzi, G., Kelso, J., St. Pourcain, B., 
Hublin, J.-J., Franke, B., Pääbo, S., Macciardi, F., Grabe, H. J, Fisher, S. Neandertal Introgression Sheds Light on Modern Human Endocranial Globularity, Current Biology 29, 2019, pp. 120-127.

20. Hare, B., Wobber, V., Wrangham, R. The Self-Domestication Hypothesis: Evolution of Bonobo Psychology Is Due to Selection against Aggression, Animal Behaviour 83, 2012, pp. 573-85.

21. Harris, E. E. Ancestors in Our Genome: The New Science of Human Evolution, Oxford University Press, 2015.

22. Hicks, J. M., Coolidge, F. L. On the Role of Precuneal Expansion in the Evolution of Cognition, Published online, University of Colorado, Center for Cognitive Archaeology, Colorado Springs, 2016.

23. Hublin, J.-J., Ben-Ncer, A., Bailey, S. E., et al. New fossils from Jebel Irhoud, Morocco and the pan-African origin of Homo sapiens, Nature 546, 2017, pp. 289-292.

24. Lachance, J., Tishkoff, S. A. Population Genomics of Human Adaptation. Annual Review of Ecology, Evolution, and Systematics 44, 2013, pp. 123-43.

25. Lang, S. Men as Women, Women as Men: Changing Gender in Native American Cultures, University of Texas Press, 1998.

26. Marx, K. A Contribution to the Critique of Hegel's Philosophy of Right. Press Syndicate of the University of Cambridge, 1967 [orig. 1843].

27. Newberg, A. B. Principles of Neurotheology, Ashgate Publishing Limited, 2010.

28. Otto, R. The Idea of the Holy, Oxford University Press, 1923.

29. Pääbo, S. Neanderthal Man: In Search of Lost Genomes, NY: Basic Books, 2015.

30. Pew Research Center. The Religious Landscape Studies, online, 2012.

31. Why Americans Go (and Don’t Go) to Religious Services, online, 2018.

32. Rappaport, M. B., Corbally, C. The Human Hearth and the Dawn of Morality, Zygon: Journal of Religion and Science 51, 2016, pp. 835-866.

33. Human Phenotypic Morality and the Biological Basis for Knowing Good, Zygon: Journal of Religion and Science 52, 2017, pp. 822-846.

34. Evolution of Religious Capacity in Genus Homo: Origins and Building Blocks, Zygon: Journal of Religion and Science 53(1), 2018a, pp. 123-158.

35 . Evolution of Religious Capacity in the Genus Homo: Cognitive Time Sequence, Zygon: Journal of Religion and Science 53, 2018b, pp. 159-197.

36. Evolution of Religious Capacity in the Genus Homo: Trait Complexity in

Action through Compassion, Zygon: Journal of Religion and Science 53, 2018c, pp. 198-239.

37. In press. Importance of the Activation and Deactivation of the Precuneus in

Human Theological Thinking and Experience of Immanence and Transcendence, Studies in Science and Theology, ESSSAT, 2019.

38. In press. Cultural Neural Reuse, Re-deployed Brain Networks, and Homologous Cultural Patterns of Compassion, Proceedings, Illuminating Biological Systems from a Network Perspective, University of Namur Press, 2019.

39. Rendu, W., Beauval, C., Crevecoeur, I., Bayle, P., Balzeau, A., Bismuth, T., Bourguignon, L. et al. Evidence Supporting an Intentional Neandertal Burial at La Chapelle-aux-Saints, Proceedings of the National Academy of Sciences 111, 2014, pp. 81-86.

40. Sack, A. T. Parietal Cortex and Spatial Cognition. Behavioural Brain Research, 2009, pp. 153-61.

41. Smaers, J. B., Turner, A. H., Gómez-Robles, A., Sherwood, C. C. A Cerebellar Substrate for Cognition Evolved Multiple Times Independently in Mammals, eLife Sciences 7, 2018.

42. Spreng, R. N., Mar, R. A., Kim, A. S. N. The Common Neural Basis of Autobiographical Memory, Prospection, Navigation, Theory of Mind and the Default Mode, Journal of Cognitive Neuroscience 21, 2008, pp. 489-510.

43. Tanabe, H .C., Kubo, D., Hasegawa, K., Kochiyama, T., Kondo, O. Cerebellum: Anatomy, Physiology, Function, and Evolution. Digital Endocasts, Replacement of Neaderthals by Modern Humans Series, Eds. Emiliano Bruner et al., Springer Japan, 2018, pp. 275-289. 
44. Todd, R. M., Ehlers, M. R., Müller, D. J., Robertson, A., Palombo, D. J., Freeman, N., Levine, B., Anderson, A. K. Neurogenetic Variations in Norepinephrine Availability Enhance Perceptual Vividness, Journal of Neuroscience 35, 2015, pp. 6506-6516.

45. Todd, R. M., Müller, D. J., Palombo, D. J., Robertson, A., Eaton, T., Freeman, N., Levine, B. Anderson, A. K. Deletion Variant in the ADRA2B Gene Increases Coupling between Emotional Responses at Encoding and Later Retrieval of Emotional Memories, Neurobiology of Learning and Memory 112, 2014, pp. 222-229.

46. Toffler, A. Future Shock, A Bantam Book, 1970.

47. Wynn, T., Coolidge, F. L. How to Think Like a Neandertal, Oxford University Press, 2012.

48. Zhang, S., Li, C. R. Functional Connectivity Mapping of the Human Precuneus by Resting State fMRI, Neuroimage 59, 2012, pp. 3548-3562.

\section{Notes}

1. We specify "adult" behavior and cognition because many children cannot always distinguish between fantasy and reality. Since religious experience sometimes involves altered states of consciousness that mix real and unreal, conscious and unconscious, dream and wakefulness, we believe it is reasonable to specify that only adult humans experience "religious thinking". Of course, children can begin to learn about religion early, and practice religious activities, but religious thinking is a domain primarily for adults. 